\title{
BEYAZ NOKTA LEZYONLARI
}

\section{WHITE SPOT LESIONS}

Makale Kodu/Article code: 4200

Makale Gönderilme tarihi: 31.10 .2019

Kabul Tarihi: 13.08.2020

Gamze Kes : ORCID ID: 0000-0003-3114-8967

DOI : $10.17567 /$ ataunidfd.780061

Öz

Başlangıç mine demineralizasyonu, minedeki mineral kaybının neden olduğu optik ilüzyon sonucunda beyaz nokta lezyonu olarak görülür. Bu lezyonların teşhisi zor olabileceğinden, tanı için birçok yöntem geliştirilmiştir. Bu derlemede beyaz nokta lezyonlarının tanı ve tedavi planlaması için güncel yöntemler incelenmiştir.

Anahtar Kelimeler: Beyaz Nokta Lezyonları, Rezin İnfiltrant, Remineralizasyon, Lazer Floresans

\section{ABSTRACT}

Initial enamel demineralization is also seen as a white spot lesion as a result of optical illusion caused by mineral loss in the enamel. Since these lesions can be difficult to diagnose, many methods have been developed for diagnosis. In this review, current methods for diagnosis and treatment planning of white dot lesions are examined.

Key Words: White Spot Lesions, Resin İnfiltrant, Remineralization, Laser Fluorescence

\footnotetext{
* Hacettepe Üniversitesi Diş Hekimliği Fakültesi, Ankara

\section{GİRIş}

İnsanoğlunu tarih öncesi çağlardan beri etkile yen, modern zamanda ise sıklığı önemli derecede artmış olan diş çürüğü , oldukça yaygın bir kronik hastalıktır. Diş minesi ; ağız içindeki asidite değişimiyle birlikte, sürekli olarak demineralizasyon reminera lizasyon döngüsüne maruz kalmaktadır . Çürük; diş yüzeyi ile dental plak arasındaki demineralizasyon remineralizasyon döngüsünün bozulması sonucu, demineralizasyonun artması ve diş yüzeyinde mineral kaybı oluşumuyla karakterize dinamik bir olay olarak tanımlanmaktadır. Normal şartlarda minenin inorganik bileşeninde yani hidroksiapatitte oluşan bir hasar tükürükteki mineral ve enzi mlerle hızlı bir şekilde onarılmaktadır. Ancak bu dengedeki küçük bir değişim, demineralizasyona neden olarak çürük gelişimiyle sonuçlanabilmektedir. ${ }^{1}$

Günümüzde, diş hekimliği alanında yapılan çalış malar, şürüklerin tedavi edilmesin den çok koruyucu önlemlere ve erken safhalarda teşhis edilerek bu sürecin geri döndürülmesine odaklanmıştır. ${ }^{2}$ 


\section{BEYAZ NOKTA LEZYONLARININ TANIMI VE ÖZELLİKLERİ}

Başlangıç mine demineralizasyonu , minenin mineral kaybı ile oluşan optik illüzyonun so nucunda "beyaz nokta lezyonu" olarak da adlandırılmaktadır. Beyaz nokta lezyonları (BNL), kavitasyonsuz mine demineralizasyonu olarak tanımlanır. Bu belirtiler, çürüğün, geri dönüşme olasılığı olan ilk klinik gözlemini temsil eder. ${ }^{3}$

Beyaz nokta lezyonlarının histolojik özellikleri;

Beyaz nokta lezyonu mine kristallerinin çözünmesi, minede gözeneklerin oluşması ve yüzey altında demineralizasyon ile başlamaktadır . ${ }^{4}$ Etkilenmiş alandaki ışığın kırılma indeksinde oluşan değişiklik , yüzey parlaklığının kaybı, yüzey pürüzlülüğündeki artış ve, yansımadaki değişimlerin bir sonucudur . Mine opasitesinin nedeni, gözenekli minenin sağlam mineye göre daha fazla ışık yansıtmasıdır. ${ }^{5}$

Darling $^{6}$ kavitasyon oluşmamış minede yaptığı histolojik incelemede dört tabaka tespit etmiştir Darling tarafından tanımlanan başlangıç çürüğündeki 4 tabaka yüzey tabaka, lezyon gövdesi, karanlık tabaka ve saydam tabaka olarak adlandırılmıştır.

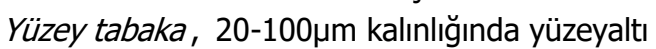
tabakalara göre nispeten etkilenmemiş mine tabaka sıdır. Bir difüzyon ortamı yaratarak minenin içine ve dışına hareket eden minerallerin geçişine izin vermek tedir. Bu yüzey tabakasında sadece \% 5- 10 oranında mineral kaybı oluşmaktadır . Ağız ortamın dan gelen iyon göçü sayesinde çözünmeye dirençlidir.

Lezyonun gövdesi yüzey tabakasının altında bulunmaktadır. \%24-\% 60 mineral kaybının oluştuğu asıl demineralizasyon alanıdır ve gelişmiş lezyonlarda radyografilerde izlenebilmektedir . Yüzey tabakaya yakın bölgede $\% 5$ olan por hacmi, gövdenin merkezine doğru \%25'e çıkmaktadır.

Karanlık tabaka lezyon gövdesinin altında yer alır. Polarize ışık mikroskobundaki koyu renkli görüntü sünden dolayı bu şekilde isimlendirilmiştir . Buradaki demineralizasyon miktarı, \%6 kadardır. Karanlık tabakası geniş beyaz nokta lezyonlarında daha uzun süreli remineralizasyon tedavisi gerekmektedir. Beyaz lezyonlarda remineralizasyonun gözlendiği tabakalar karanlık tabaka ve yüzey tabakadır .

Saydam tabaka karanlık tabakanın altında yer almaktadır. \% 1-2 arasında mineral kaybı vardır. ${ }^{2,6}$

Beyaz nokta lezyonu olan minede ， sağlam mineye göre daha büyük çapta por alanı varlığı polarize ışık mikroskobu ile gözlenmektedir Beyaz nokta lezyonlarında görülen porlar plak asitlerinin yüzey altı tabakalara ulaşmasına neden olmaktadır . Bu derinlikte minede yüzey altı çözünmesi meydana geldiği bildirilmektedir. $^{7}$

Beyaz nokta lezyonlarının klinik özellikleri :

-Dehidrate olduğunda, tebeşirimsi beyaz görünüme sahip minenin, normal translüsentliği kaybolmuştur,

-Özellikle pit ve fissürlerde, sondlamaya karşı hassas, kırılgan bir yüzey katmanı vardır,

renklenme potansiyeli yüksektir ve yüzeyaltında gözeneklilik artmıştır,

-Transillüminasyonla, diod lazer cihazlarıyla veya radyografik olarak tespit edilebilen yüzeyaltı densite azalmıştır. ${ }^{8}$

Beyaz nokta lezyonlarının ayırıcı tanısında, hava spreyi ile lezyonun kurutulması, görsel ve sondla mua yene önemlidir. BNL yüzey nemli iken translusent gö rünürken, hava spreyi ile kurutulduklarında opak beyaz renkte gözlenir . Hipokalsifiye defektler ise ortamın nemli ya da kuru olmasından etkilenmezler ve yüzey nemli iken de opak beyaz renktedir . Her iki lezyonun da yüzeyinde kavitasyon olmamasına rağmen , BNL yüzeyi daha yumuşak ve pürüzlüdür. ${ }^{9}$

Çürük oluşumu için biofilm gerekli olduğundan beyaz nokta lezyonları plak ile örtülü yüzeylerin altında gelişirler ki bu bölgeler genellikle kontakt bölgeleri ile ilişkili olan ara yüzeyler ve fasi yal ve lingual yüzeylerin gingival üçlüleridir . ${ }^{10}$ Beyaz nokta lezyonlarının ortodontik tedavi gören hastalarda sıklıkla gözlendiği bildirilmiştir. Birinci molar dişler , üst lateral kesiciler , alt kanin dişler beyaz nokta lezyonlarından en çok etkilenen diş grubunu oluşturmaktadırlar. ${ }^{11}$

\section{BEYAZ NOKTA LEZYONLARININ TEŞHİSİ}

Çürük teşhisi, tedavi planlamasının ilk adımını oluşturmaktadır. Basit, güvenilir, geçerli, sensitif ve spesifik, non-invaziv bir yöntem ile çürüğün mikros kopik düzeyde saptanabilmesi ve erken tedavisi diş hekimlerinin önceliği olmalıdır. ${ }^{12}$

\section{Görsel ve Radyografik Değerlendirme}

İyi aydınlatılmış yüzeyde gözle muayene , sond ve radyografi uzun yıllardır teşhis amacıyla kullanıl maktadır. Geçmişte sondla mu ayene, restorasyon endikasyonu koymak amacıyla kullanılsa da günümüzde kavitasyon göstermeyen yüzeylere zarar verebileceği gerekçesiyle tercih edilmemektedir . Ayrıntılı görsel in dekslerin kullanımı ile muayene eden kişinin yorumunu en aza indirmek ve tekrarlanabilirliği arttırmak mümkündür. ${ }^{13}$ 
Çürük lezyonlarının kaydı, ideal olarak, lezyonları ilerleme evresine göre sınflandıran bir sisteme dayanmalıdır. Dünyada diş çürüğü prevalansının artmasıyla, çürük teşhisi için daha hassas sistemlerin geliştirilmesi zorunlu hale gelmiştir. Çürük indeksleri, kavitasyonsuz mine lezyonlarındaki translüsensi değişikliklerinden, büyük kavitelere kadar lezyonları kapsamaktadır. ${ }^{14}$ Skorlama kriterleri farklı olmasına rağmen, tüm sınıflandırmaların temel amacı uluslararası anlamda kabul gören değerlendirme ölçütleri oluşturmak ve kanıta dayalı bir çürük belirleme olanağı sağlamaktır. ${ }^{15}$

\section{Lazer Floresans}

Sağlıklı mine ve dentin, demineralize dokulara kıyasla farklı floresans özellikler göstermektedir. Çünkü demineralize dokular ışığı daha az absorbe ederek ve daha fazla yansitarak, daha az floresans özellik göstermektedir. ${ }^{16}$

Bu sistemde en bilinen marka DİAGNOdent'tir

(KaVo, Biberach, Almanya). Bu aletle diş yüzeyi diod lazer ışı̆ı yardımıyla aydınlatılm akta ve yüzeyden yayılan fluoresans analiz edilip ölçülmektedir 0-99 arasında bir numerik değer ortaya çıkmaktadır . Derin çürüklerde değer daha yüksektir. ${ }^{17}$

Caries ID, (Midwest Caries ID, DENTSPLY Professional, New York, Amerika) çürüğü tespit etmek ve ölçmek için kullanılan, küçük, pille çalışan ve kolayca dezenfekte edilebilen bir cihazdır. Üreticiye göre, mine prizmalarının yapısal bütünlüğünü analiz ederek hipokalsifikasyonu tespit etmektedir. ${ }^{18}$ Krause ve ark.; Caries ID ile radyografik bulguları karşılaştıılarak yaptıkları çalışmada \% 100 duyarılıı bildirmiştir. ${ }^{19}$ Görsel yötem ve Caries ID ile histolojik incelemeleri karşılaştıran bir çalışmada, Caries ID nin çürüğü tespit etmede optimal olmadığı fakat sağıkı diş yapısını belirlemede oldukça güvenilir olduğu gösterilmiştir fakat bu cihazların görsel yöntemle birlikte uygulandığında başarıı olacağı bildirilmiştir. ${ }^{18}$

Klinik bir çalışmanın sonucunda; beyaz nokta lezyonlarında DIAGNOdent Pen'in güvenilir ve ICDAS kriterleri ile uyumlu olduğu bulunmuştur. ${ }^{20}$ DİAGNOdent Pen ile Caries ID yi karşılaştıran bir çalışmada; Caries ID nin çürük saptamada daha başarıı olduğu ancak çürük olmadığı durumda DİAGNOdent e göre daha fazla yanlış pozitif cevap verdiği bulunmuştur. ${ }^{21}$

\section{Elektronik Çürük Monitörü (ECM)}

Elektriksel iletkenlik yönteminin esası, sağlıklı ve demineralize dokular arasındaki iletkenlik farkına dayanmaktadır. Sağlam mine yüzeyleri sınırlı iletkenliğe sahipken, demineralize ve çürük mine yüzeyleri, ağız sıvılarına geçirgenliğin artmasından dolayı ölçülebilir iletkenliğe sahiptir ve demineralizasyon arttıkça iletkenlik artmaktadır. Diş dokusunun elektriksel iletkenliğinin yüzeyde madde kaybının olmadığı beyaz nokta lezyonlarında bile değişkenlik gösterdiği tespit edilmiştir. ${ }^{22}$

\section{Alternatif Akım Empedans Spektroskopi}

Beyaz nokta lezyonlarının teşhisinde kullanılabilen elektriksel bir yöntemdir. Elektronik çürük monitörü ile benzer prensiple çalışmaktadır. Kavitasyon oluşmamış mine lezyonlarının teşhisinde $\% 100$ hassasiyete sahip olduğu bildirilmiştir. Bu prensiple çalsşan CarieScan Pro(CarieScan Ltd, Dundee, İskoçya) isimli bir cihaz bulunmaktadır. ${ }^{23}$

\section{Canary Sistemi}

Canary, ISı ve ışığı birlikte kullanarak diş yapısının ve çürüğün görüntülenmesinde kullanılan bir lazer sistemidir. ${ }^{24}$ Diş çürüğünün varlığı, düşük güçte lazer ışı̆ı ile dişlerin taranmasıyla saptanmaktadır. Dişin lazer ışı̆ını soğurmasının ardından dişe zarar vermeyecek düzeyde bir ISı meydana gelmektedir. Yansıyan ısı ve ışı̆̆ın eş zamanlı ölçümü ile diş yüzeyi altındaki çürüğün varlığı ve boyutu hakkında bilgi sağlanabilmektedir. ${ }^{25}$

\section{Fiber Optik Transiluminasyon (FOTİ)}

FOTİ mine yapısında ışık saçılma özelliğine dayanan bir teşhis yöntemidir, DI-FOTİ ise geliştirilmiş dijital versiyonudur. Mine çürüğünün sağlıklı mineye göre ışık geçişinde daha düşük indekse sahip olması esasına dayanmaktadır. ${ }^{26}$ Sistemin en büyük özelliği kolay uygulanabilen, kesin ve tekrarlanabilen ölçümler yapabilmesidir. ${ }^{27}$

\section{Kantitatif Işık Etkili Floresans (QLF)}

Bu yöntem özellikle düz yüzeylerde başarılı so nuçlar vermektedir. ${ }^{28}$ Sağlam bölgeler ve demineralize bölgeler arasındaki fark karşılaştırıır ve $\% 5$ 'ten fazla floresans kaybı lezyonun varlığını tanımlamaktadır. ${ }^{29}$

\section{Floresans Kamera}

Floresans kamera, dişi mor renkli bir ışıkla aydınlatarak yansıyan ışığı dijital görüntü olarak kaydeden, ağız içi bir kameradır. ${ }^{30,31} 2018$ yılında yapılan bir çalışma Floresans kameraların, beyaz nokta lezyonlarının optik özelliklerini ve rezin infiltrasyon tedavisinin bu özellikler üzerindeki etkisini değerlendirmek için kullanılabileceğini göstermiştir. ${ }^{32}$ 
Klinikte çürük teşhisi ve tedavisi için geliştirilen yöntemler, erken dönemde lezyonun belirlenmesini amaçlamaktadır. ${ }^{33}$ BNL tespiti ve izlenmesi için ideal yöntem klinikte kolayca uygulanabilir, hastaya maliyet açısından uygun ve zararsız olmalıdır. ${ }^{34}$

\section{BEYAZ NOKTA LEZYONLARININ TEDAVİSİ}

$B N L$ tedavisinde iki seçenek vardır:

Birincisi koruma ve lezyonların remineralizasyonuna dayanır.

İkinci strateji beyazlatma, mikro-abrazyon veya rezin infiltrasyon gibi minimal invaziv önlemler ile dişlerin estetik görünümünü maskelemeyi ve iyileştirmeyi amaçlar. ${ }^{35,36}$ En iyi tedavinin seçimi kritiktir çünkü remineralizasyon dışındaki tedaviler diş yapısında geri dönüşü olmayan hasara neden olabilmektedir. ${ }^{37}$

Yüzey tabakası bozulmamış kaldığı sürece lezyonun remineralizasyonu mümkündür ve restoras yon yapılmaksızın tamir gerçekleşebilmektedir . Öte yandan ancak mine ile sınırlı daimi diş lezyonlarının remineralizasyonla iyileşebileceği dikkate alınmalıdır. ${ }^{38}$

\section{Plak Kontrolü}

Mekanik yöntemlerle birlikte antimikrobiyal solüsyonların biofilmin elimine edilmesinde kullanımı bilinmektedir. ${ }^{39}$ Florür ve $\mathrm{CHX}^{\prime}$ in etki mekanizmaları farkıdır ve kombine kullanıldıklarında oluş an sinerjik etki mine ve dentinde optimal düzeyde korunma sağla maktadır. Klorheksidin ve florür içeren verniklerin birlikte kullanılmasının başlangıç yüzeylerinin remineralizasyonunda daha başarılı olduğu saptanmıştır. ${ }^{40}$

\section{Florür İçermeyen Mine Remizeralizasyon Teknikleri}

\section{Dentin Fosfoprotein}

Dentin fosfoprotein (DPP), dentindeki en yüksek miktarda non-kollajen ekstraselüler matriks bileşenidir ve diş mineralizasyonunda kritik bir rol oynadığı bilinmektedir. Yakın zamanda yapılan bir in vitro çalışma, biyomimetik peptidinin, mine demineralizasyonunu kendi başına inhibe etmenin yanı sıra, florürün etkisini de önemli ölçüde artırabileceğine dair güçlü kanıtlar sağlamışıı. Bu sinerjik etkileşim, çocuklarda dental florozis riskinin azaltımasında faydalı olabilmektedir. ${ }^{41}$

\section{Elektriksel Olarak Hızlandırılmış ve Geliştirilmiş Remineralizasyon (EAER)}

Elektriksel olarak hızlandırılmış ve geliştirilmiş remineralizasyon (EAER), sağlıklı dokuyu korumak, çürük lezyonunun tüm derinliğini restore etmek ve tedavi edilmiş minenin mekanik özelliklerini iyileştirmek amacıyla, başlangıç ve orta dereceli mine lezyonlarını hedef alan bir remineralizasyon teknolojisidir. Remineralize edici iyonların yüzeyaltı çürük lezyonunun en derin kısmına akışını hızlandırmak için iyontoforezi kullanır. Bu yöntemle tedavi edilen lezyonlar, taramalı elektron mikroskobu altında, sağıklı mine ile çok benzer bir görünüme sahip bulunmuştur. ${ }^{42}$

\section{Nano Hidroksiapatit}

Hidroksiapatitin insan dişine benzer kristal yapı gösterdiğinin anla şıması üzerine diş macunları , gargara ve benzeri ajanlara nano-hidroksiapatilerin eklenmesinin, başlangıç çürük lezyonlarında remineralizas yon potansiyeli sağladığı belirtilmektedir $\quad .^{43} \quad$ Nano Hidroksiapatitin mine onarımı veya yenilenmesi için ümit verici bir yaklaşım olduğu belirtilmektedir. ${ }^{44}$

\section{Self Assembling Peptid P11-4}

Remineralizasyondaki en son gelişme, erken çürük lezyonlarının rejeneratif tedavisi için kendinden birleşen peptidleri (P11-4) kullanan Curolox (Curodont RepairTM, Credentis AG, Windisch, İsviçre) teknolojisidir. ${ }^{45}$ Bir klinik çalışmanın sonucunda, P11-4'ün florür ile kombinasyon halinde kolaylaştırdığı biyomimetik mineralizasyonun erken çürük lezyonları için basit, güvenli ve etkili bir noninvaziv tedavi olduğu ve klinik altın standardı olan florür tedavisinden üstün olduğu gösterilmiştir. ${ }^{46}$

\section{Kazein Fosfopeptid - Amorf Kalsiyum Fosfat (CPP-ACP)}

Kalsiyum fosfat remineralizasyon sistemleri piyasada farklı ürün şekilerinde bulunmaktadır . Bunlardan biri kazein fosfopeptidin stabilize ettiği amorf kalsiyum fosfat, diğeri stabilize olmayan amorf kalsiyum fosfat , son olarak da kalsiyum sodyum fosfosilikattır . Bütün ürünler kalsiyum fosfat bileşiğinden oluşmakta ve etki lerini, tükürüğün remineralizasyonu sağla yacak doğal kapasitesini arttırarak göstermektedirler . Bunların arasında CPP-ACP üzerinde en fazla araştırma yapılmış üründür. ${ }^{47}$

\section{Trikalsiyum Fosfat}

Son yıllarda üretilen diş macunlarının yapısına katılan trikalsiyumfosfat, sodyum lauril sülfatı $\mathrm{n}$ kalsi- 
yumla modifiye edilmesi sonucu elde edilmiştir $\quad$. $^{48}$ Karlinsey ve ark . başlangıç mine lezyonlarının remi neralizasyonuyla ilgili yaptıkları in vitro çalışmada trikalsiyum fosfatın florürlü diş macunlarından daha etkili remineralizasyon sağla dığını bildirmiştir . ${ }^{49}$ Plasebo kontrollü klinik çalışmalar, yalnızca florüre kıyasla, florür eklenerek etkinliği artırımış TCP kombinasyonunun, hem beyaz nokta lezyonlarının hem de aşınmış minelerin remineralizasyonunu artırabileceğini göstermiştir. ${ }^{50,51}$

\section{Biyoaktif Cam}

Yakın zamanlarda, dental kullanım için bir biyoaktif cam geliştirilmiştir ve BNL'lerin remineralize edilmesi için birçok çalışma içerisinde uygulanmıştır. ${ }^{52,56}$

Biyoaktif camın gelişimi ve başarısı , materyalin yüksek biyouyumlul uk özelliğinden ileri gelmektedir . Novamin, sulu çözeltiler içerisinde bulunan bir biyoaktif camdır. Biyoaktif cam içerikli macunlar, BNL'ler için başarılı bir remineralize edici madde olarak büyük potansiyele sahiptir. ${ }^{57}$ Biyoaktif camların mine remineralizasyonu üzerindeki etkisini araştıran bir çalışmada; biyoaktif camların, formülasyon veya uygulama şekli ne olursa olsun, florür ve CPP-ACP gibi diğer topikal ajanlarla karşılaştırıldığında mine remineralizasyonunda daha etkili olduğu bulunmuştur. ${ }^{58}$

\section{Florür Uygulamaları}

Florür uygun şekilde kullanıldığında , hem diş çürüklerinin önlenmesinde hem de diş çürüklerini kontrol etmede oldukça güvenli ve etkili bir yöntem dir. ${ }^{59}$ Florür ürünlerinin diş çürüğünün önlenmesindeki rolünü doğrulayan çoklu sistematik incelemelerle çürük lezyonlarının önlenmesi için altın standart olmaya devam etmektedir. ${ }^{60}$

Topikal florürün beyaz nokta lezyonuna uygulanması, çoğu klinisyen tarafından tedavide ilk adım olarak kabul edilir. Tedavi amaçlı yüksek florür konsantrasyonunun uygulanması yüzeysel mine tabakasını remineralize edebilir, ancak daha derin mine kristalleri nispeten etkilenmeden kalabilmektedir Bu nedenle, tedavi için ilk önce düşük florür konsantrasyonlarının uygulanması tavsiye edilmektedir. ${ }^{61}$

Gökçe ve ark. yapay lezyonlar yaratarak ve bunları florürlü diş macunu, novamin içerikli diş macunu ve probiyotik içerikli diş macunu ile tedavi ederek, diş macunlarının beyaz nokta lezyonları üzerindeki etkilerini değerlendirmiş ve novamin içerikli diş macununun diğerlerine kıyasla artmış bir floresans gösterdiğini gözlemlemişlerdir. ${ }^{62}$

Remineralizayon başı başına bir araştırma konusu olmasına rağmen , tüm geliştirilmiş çürükten korunma metodları içinde hangisinin daha yararlı olacağını söylemek mümkün değildir . Fluorür uygulamaları halen en popüler çürükten korunma metodu olarak gözükmektedir. ${ }^{63}$

\section{Düşük Viskoziteli Rezinler}

Başlangıç çürük lezyonlarına ışıkla sertleşen düşük viskoziteli rezinlerin infiltrasyonu son yıllarda uygulanan yeni bir tedavi yöntemidir. Düşük viskoziteli rezinlerin kullanılmasının amacı rezinin lezyon gövdesine penetrasyonunu sağlayarak porları kapatmaktır ve lezyonun ilerlemesini durdurabilmektedir. Ayrıca rezinin ışıkla sertleştirilmesiyle lezyon bölgesindeki kırılgan mineye mekanik destek sağlanır. Böylece kavitasyonlar önlenebilmektedir. ${ }^{64} \mathrm{Bu}$ işlem hem interproksimal lezyonlarda hem fasial yüzeylerdeki BNL üzerinde uygulanabilmektedir. ${ }^{65}$

Bir çok araştırmacı yüzeysel arayüz lezyonla rının tedavisinde rezin infiltrasyon uygulamasını önermektedir. ${ }^{66}$ Martignon ve arkadaşları tarafından yapılan randomize klinik çalışmada, infiltrasyon/sealing uygulamaları ara yüzey lezyonlarının ilerlemesinin 3 yıllık takibi sonucunda, mine dentin sınırındaki veya dentinin 1/3 dış tabakasındaki aktif çürük lezyonla rında, rezin infiltrasyonun modern girişimsel olmayan yöntemler arasında yerini alması önerilmiştir. ${ }^{67}$

Rezin infiltrasyonunun, 2 ve 6 ay takip sürelerini anlatan iki çalışmada, BNL'ların tedavi edilmeyen lezyonlarla karşılaştırıldığında anında iyileştirilmiş bir estetik görünümü sağladığı bulunmuştur. ${ }^{68,69}$ Bir başka in vitro çalışmada ise; rezin infiltrasyonun beyaz nokta lezyonlarındaki bozulmamış minenin estetiği ve flüoresansını yeniden kazandırdığı gösterilmektedir. ${ }^{70}$ Rezin infiltrasyon tekniğinin estetiği geliştirdiğini söyleyen iki farklı çalışmada, tekniğin diğer yöntemlerden üstün olduğu belirtilmiştir. ${ }^{71,72}$

Rezin infiltrasyon prosedürü, koruyucu tedaviler ve invaziv geleneksel restoratif tedaviler arasındaki boşluğu kapatmaktadır. Daha az invaziv estetik tedavilere olan talebin artmasıyla, rezin infiltrasyonu, mine beyaz nokta lezyonunun tedavisi için yeni bir alternatiftir. $^{73}$

\section{Lazer Uygulamaları}

Lazerlerin hidroksiapatit kristallerinde erime ve kaynaşmaya neden olarak mine yüzeyinin asitlere direncini artırdığı öne sürülmüştür. In vitro ve in situ çalışmalarda CO2 lazerin yüzeyaltı minenin demineralizasyonunu azalttığ ${ }^{74}$ ve florür uygulamarıyla birlikte kullanıldığında bu etkinin arttığı bildirilmiştir. ${ }^{75,78}$

Mahmoudzadeh ve ark., $\mathrm{CO}^{2}$ lazer ve florür verniğinin minenin yüzey mikro sertliği üzerindeki 
etkisine ilişkin bir çalışma yürütmüştür. Dişler 5 farklı gruba ayrımıştır: florür vernik, $\mathrm{CO}^{2}$ lazer, lazer sonrası vernik, vernik sonrası lazer ve kontrol grubu. Bu çalışmada, florür ve lazer kombinasyonlarının mine mikro sertliği açısından en iyi sonucu verdiği belirtilmiştir. ${ }^{79}$

\section{Mikroabrazyon}

Mine mikroabrazyonu , remineralizasyonu sağlamak, renklenmeleri gidermek ve diş yüzey do kusunu geliştirmek için tasarlanmış bir tekniktir Lezyonun yüzeysel tabakasının jel kıvamlı hidroklorik asit ve pomza ile aşındırılarak uzaklaştııı Imasıyla , mine yüzeyi düz ve parlak hale gelmektedir . Mikroabrazyonun minenin kusurlu dış tabakasını ortadan kaldırarak, dişlerin görünümünü iyileştirebileceği bildirilmiştir. ${ }^{80}$ Klinik çalışmalar, BNL'larında iyi bir estetik sonuç elde etmek için mikroabrazyonun kullanılmasının yararını doğrulamıştı ${ }^{81}$ Ancak, bu teknik ile görünümü iyileştirmek için ne yazık ki önemli miktarda mine dokusunun uzaklaştıııması gerekmektedir . Oysa ki rezin infiltrasyon tekniğinde hidroklorik asit jel ile sadece hipermineralize yüzey tabakası kaldırılırken, düşük viskoziteli rezinin lezyonun derinliklere kadar penetre olması sağlanabilmektedir. ${ }^{82}$

Rezin infiltrasyon ve mikroabrazyonun BNL'larının estetik görünümü üzerinde etkisini inceleyen bir çalışmanın sonuçları şu şekildedir: 12 aylık gözlem periyodunda rezin infiltrasyon hemen başlayan ve uzun dönem stabil olan estetik bir iyileşmeye sahipken, mikroabrazyon takip döneminde belirgin iyileşme göstermiştir.12 aylık takipten sonra, BNL'larının estetik gelişimi için, rezin infiltrasyon mikroabrazyona kıyasla daha etkili görünmektedir. ${ }^{83}$

\section{Beyazlatma}

Mikroabrazyon ile istenen estetik elde edilemez ise beyazlatma tedavisi düşünebilir ${ }^{84}$ Bu prosedürdeki amaç beyaz nokta lezyonların çevresindeki mine yüzeylerini beyazlatarak kamuflaj sağlamaktır. ${ }^{85}$

Bir in vitro çalışmada, beyazlatmanın başlangıç çürüğü olan dişlerdeki demineralizasyon derinliğini önemli oranda artırmadığı bildirilmiş olsa da, bazı araştırmacılar, beyazlatma tedavisi sırasında florlama işleminin yapılmasını önermektedir. ${ }^{86}$ Başka bir in vitro çalışmada; ev veya ofis tipi diş beyazlatma işleminin florürlü ya da florür olmaksızın, beyazlatmadan sonra sağlam mine ve BNL alanları arasındaki renk farkının azaldığı gösterilmiştir. Florür uygulamasının, beyazlatmanın etkilerini azaltmadan dişlerin reminerizasyonunu artırabileceği belirtilmiştir. ${ }^{87}$

\section{Restoratif İșlemler}

Kompozit restorasyonlar ve porselen veneerler hastanın estetik beklentisini karşılamak için son se çenektir. Bu tedavi sağlıklı diş dokusunun uzaklaştırımasını içermektedir ve maliyeti daha yüksektir . Fakat, çok şiddetli d urumlarda estetik olarak en beğenilen sonucu oluşturmaktadır. ${ }^{88,89}$

\section{SONUÇ}

Başlangıç çürük lezyonlarının ilk bulgusu olan beyaz nokta lezyonlarının ， erken dönemde teşhis edilerek henüz kavitasyon oluşmadan tedavi edilmesi , minimal invaziv diş hek imliğinin önemli basamak larından bir tanesidir . Erken aşamada fark edilen bu lezyonların remineralizasyon yoluyla tedavi edilmesi, en vazgeçilmez yöntemdir. ${ }^{90}$

NOT: Bu makale yazarlarından hiçbirinin makalede bahsi geçen konu veya malzemeyle ilgili herhangi bir ilişkisi, bağlantısı veya parasal çıkar durumu söz konusu değildir.

\section{KAYNAKLAR}

1. Lubarsky GV, D'Sa R, Deb S, Lemoine P. The role of enamel proteins in protecting mature human enamel against acidic environments: a double layer force spectroscopy study. Biointerphases 2012; 7: 14.

2. Guerrieri A, Gaucher C, Bonte E, LasfargueS JJ. Minimal intervention dentistry: part 4. Detection and diagnosis of initial caries lesions. $\mathrm{Br}$ Dent $\mathrm{J}$ 2012; 213:551-7.

3. Paula aB, Fernandes ar, Coelho as, et al. therapies for white spot lesions-a systematic review. J Evid Based Dent Pract 2017; 17:23-38.

4. Murdoch-Kinch CA, McLean ME. Minimally invasive dentistry. J Am Dent Assoc 2003;134:87-95.

5. Edckstein A, Helms HJ , Knösel M . Camouflage effects following resin infiltration of postorthodontic white-spot lesions in vivo: oneyear follow-up. Angle Orthod 2015; 85:374-80.

6. Darling Al. The selective attack of caries on the dental enamel. Ann R Coll Surg Engl 1961;29:35469.

7. Melberg JR, Ripa LW. Formation of dental caries. In Fluoride in Preventive Dentistry. Theory and clinical applications. p:15-40. Chicago, Quintessence Publishing Co, 1983.

8. Mount GJ. Defining, classifying, and placing Incipient caries lesions in perspective. Dent Clin North Am 2005;49:701-23. 
9. Belli R, Christos R, Edward WS, Luiz NB, Anselm P, Ulrıch R. Wear and morphology of infiltrated white spot lesions. J Dent 2011; 39: 376-85.

10. Zero DT, Zandona AF, Vail MM, Spolnik KJ. Dental caries and pulpal disease. Dent Clin North Am 2011; 55: 29-46.

11. Tantradi $P$, Sreenivasan V, Kadaganche H. Role of bitewing in enhancing the assessment of DMFS index in a group of Indian adolescents. Indian J Dent Res 2010; 21: 266-269

12. Stookey G. Should a dental explorer be used to probe suspected carious lesions? No--use of an explorer can lead to misdiagnosis and disrupt remineralization. J Am Dent Assoc 2005; 136: 1527, 1529, 1531.

13. Braga MM, Oliveira LB , Bonini GA, Bönecker M, Mendes FM. Feasibility of the International Caries Detection and Assessment System (ICDAS-II) in epidemiological surveys and comparability with standard World Health Organization criteria. Caries Res 2009; 43: 245-9.

14. Ismail AI, Sohn W, Tellez M, Amaya A, Sen A, Hasson $\mathrm{H}$. The International Caries Detection and Assessment System (ICDAS): an integrated system for measuring dental caries. Community Dent Oral Epidemiol 2007; 35: 170-8.

15. Ekstrand KR, Martignon S, Ricketts DJ, Qvist V. Detection and activity assessment of primary coronal caries lesions: a methodologic study. Oper Dent 2007; 32:225-35.

16. Lussi A, Megert B, Longbottom C, Reich E, Francescut $P$. Clinical performance of a laser fluorescence device for detection of occlusal caries lesions. Eur J Oral Sci 2011; 109: 14

17.Gurbuz T, Yilmaz Y, Sengul F. Performance of laser fluorescence for residual caries detection in primary teeth. Eur J Dent 2008; 2: 176-84.

18. SA Patel WD Shepard JA Barros CF Streckfus RL Quock. In Vitro Evaluation of Midwest Caries ID: A Novel Light-emitting Diode for Caries Detection Operative Dentistry 2014; 39: 644-51.

19. Krause F, Melner DJ, Stawirej R, Jepsen S, Braun A. LED based occlusal and approximal caries detection in vitro. J Dent Res 2008; 87(Special Issue $B$ ): Abstract 0526.

20. Almosa NA, Lundgren T, Aldrees AM, Birkhed D, Kjellberg $H$. Diagnosing the severity of buccal caries lesions in governmental and private orthodontic patients at debonding, using the ICDAS-II and the DIAGNOdent Pen. Angle Orthod 2014; 84:430-6.
21. Aktan AM, Cebe MA, Ciftci ME, Sirin Karaarslan E. A novel LED-based device for occlusal caries detection. Las Med Sci 2012; 27 1157-63.

22. Lussi A, Imwinkelried S, Pitts N, Longbottom C, Reich E. Performance and reproducibility of a laser fluorescence system for detection of occlusal caries in vitro. Caries Res 1999; 33: 261-6.

23. Jayarajan J, Janardhanam $\mathrm{P}$, Jayakumar $\mathrm{P}$. Efficacy of CPP -ACP and CPP -ACPF on enamel remineralization - an in vitro study using scanning electron microscope and DİAGNOdent . Indian J Dent Res 2011; 22: 77-82.

24. Hellen A, Mandelis A, Finer Y, Amaechi BT. Quantitative remineralization evolution kinet ics of artificially demineralized human enamel using photothermal radiometry and modulated luminescence. J Biophotonics 2011;4:788-804

25. Tassery $H$, Levallois $B$, Terrer $E$, Manton DJ, Otsuki M, Koubi S, Gugnani N, Panayotov I, Jacqout P, Cuisinier F, Rechmann P. Use of new minimum intervention dentistry technologies in caries management. Aust Dent J 2013;58 Suppl 1:40-59

26. Vaarkamp J, Ten Bosch JJ, Verdonschot EH, Bronkhorst EM. The real performance of bitewing radiography and fiber- optic transillumination in approximal caries diagnosis. J Dent Res 2000; 79: 1747.

27. Zandoná AF, Zero DT. Diagnostic tools for early caries detection. J Am Dent Assoc 2006; 137; 1675-84.

28. Jablonski-Momeni $A$, Liebegall $F$, Stoll $R$, HeinzelGutenbrunner $M$, Pieper K. Performance of a new fluorescence camera for detection of occlusal caries in vitro. Lasers MedSci 2013;28:101-9.

29. Iain A Pretty†Email author, Michael McGrady†, Christian Zakian. Quantitative Light Fluorescence (QLF) and Polarized White Light (PWL) assessments of dental fluorosis in an epidemiological setting. BMC Pub Health 2012; 12: 366.

30. Jablonski-Momeni A, Liebegall F, Stoll R, HeinzelGutenbrunner M, Pieper K. Performance of a new fluorescence camera for detection of occlusal caries in vitro. Lasers MedSci 2013;28:101-9.

31 Seremidi K, Lagouvardos P, Kavvadia K. Comparative in vitro validation of VistaProof and DIAGNOdent pen for occlusal caries detection in permanent teeth. Oper Dent 2012;37:234-45. 
32. Markowitz K, Carey K. Assessing the appearance and fluorescence of resin-infiltrated white spot lesions with caries detection devices. Oper Dent 2018; 43: 10-8

33. Zandoná AF, Zero DT. Diagnostic tools for early caries detection. J Am Dent Assoc 2006; 137:167584.

34. Kavvadia K, Seremidi K, Reppa C, Makou M, Lagouvardus $P$. Validation of fluorescence devices for evaluation of white spot lesions in orthodontic patients. Eur Arch Paediatr Dent. 2018;19:83-9

35. Bergstrand F, Twetman S. A review on prevention and treatment of post-orthodontic white spot lesions - evidence-based methods and emerging technologies. Open Dent J 2011;5:158-62

36. Heymann GC, Grauer D 2013. A contemporary review of white spot lesions in orthodontics. J Esthet Restor Dent 25:85-95.

37. Kim J, Shin TJ, Kong HJ, Hwang JY, Hyun HK. High-frequency ultrasound imaging for examination of early dental caries. J Dent Res 2019; 98:363-7

38. Reynolds EC, Morgan MV. Remineralization of enamel subsurface lesions in situ by sugar-free lozenges containing casein phosphopeptide amorphous calcium phosphate. Aust Dent J 2003; 48: $240-3$.

39. O'Mullane DM, Kavanagh D, Ellwood RP et al. A 3year clinical trial of a combination of trimetaphosphate and sodium fluoride in silica toothpastes. J Dent Res 1997; 76: 1776-1781.

40. de Amorim RG, Leal SC, Bezerra AC, de Amorim FP, de Toledo OA. Association of chlorhexidine and fluoride for plaque control and white spot lesion remineralization in primary dentition. Int J Paediatr Dent 2008; 18: 446-51.

41. Yang Y, Lv X, Shi W, Zhou X, Li J, Zhang L. Synergistic inhibition of enamel demineralization by peptide 8DSS and fluoride. Caries Res 2016; 50 : 32-9.

42. Pitts NB, Wright JP. Reminova and EAER: keeping enamel whole through caries remineralization. Adv Dent Res 2018; 29: 48-54.

43. Yuan P, Shen X, Liu J, Hou Y, Zhu M, Huang J, Xu $P$. Effects of dentifrice containing hydroxyapatite on dentinal tubule occlusion and aqueous hexavalent chromium cations sorption: a preliminary study. Plus One 2012; 7: 452-83.
44. Krishnan V, Bhatia A, Varma H. Development, characterization and comparison of two strontium doped nano hydroxyapatite molecules for enamel repair/regeneration. Dent Mater 2016;32:646-59.

45. Brunton PA, Davies RP, Burke JL, Smith A, Aggeli A, Brookes SJ, Kirkham J. Treatment of early caries lesions using biomimetic self- assembling peptidesa clinical safety trial. Br Dent J 2013; 215:E6.

46. Alkilzy M, Tarabaih A, Santamaria RM, Splieth $\mathrm{CH}$. Self-assembling peptide p11-4 and fluoride for regenerating enamel. Journal of Dental Research 2018, 97:148-54.

47. Cury JA, Tenuta LM. Enamel remineralization: controlling the caries disease or treating early caries lesions? Braz Oral Res 2009; 23: 23-30.

48. Karlınsey RL, Mackey AC, Stookey GK, Pfarrer AM. In vitro assessments of experimental $\mathrm{NaF}$ dentifrices containing a prospective calcium phosphate technology. Am J Dent 2009; 22:180-4.

49. Patil N, Choudhari S, Kulkarni S, Joshi SR. Comparative evaluation of remineralizing potential of three agents on artificially demineralized human enamel: an in vitro study. J Conserv Dent 2013; 16: 116-20.

50. Karlinsey RL, Pfarrer AM. Fluoride plus functionalized $\beta$-TCP: a promising combination for robust remineralization. Adv Dent Res 2012; 24: 48-52.

51. Amaechi BT, Ramalingam K, Mensinksai PK, Narjibfard K, Mackey AC, Karlinsey RL. Remineralization of eroded enamel by a $\mathrm{NaF}$ rinse containing a novel calcium phosphate agent in an in situ model: a pilot study. Clin Cosmet Investig Dent 2010; 2:93-100.

52. Bakry AS, Marghalani HY, Amin OA, Tagami J. The effect of a bioglass paste on enamel exposed to erosive challenge. J Dent 2014; 42: 1458-63.

53. Mehta $A B$, Kumari $V$, Jose $R$, Izadikhah $V$. Remineralization potential of bioactive glass and casein phosphopeptide-amorphous calcium phosphate on initial carious lesion: an in-vitro $\mathrm{pH}$ cycling study. J Conserv Dent 2014;17: 3-7.

54. Milly H, Festy F, Watson TF, Thompson I, Banerjee A. Enamel white spot lesions can remineralise using bio-active glass and polyacrylic acid-modified bio-active glass powders. J Dent 2014; 42: 15866. 
55. Narayana SS, Deepa VK, Ahamed S, Sathish ES, Meyappan R, Satheesh Kumar KS. Remineralization efficiency of bioactive glass on artificially induced carious lesion an in-vitro study. J Indian Soc Pedod Prev Dent 2014; 32: 19-25.

56. Milly H, Festy F, Andiappan M, Watson TF, Thompson I, Banerjee A. Surface pre-conditioning with bioactive glass air-abrasion can enhance enamel white spot lesion remineralization. Dent Mater 2015; 31: 522-33.

57. Bakry AS, Tamura Y, Otsuki M, Kasugai S, Ohya K, Tagami J. Cytotoxicity of 45S5 bioglass paste used for dentine hypersensitivity treatment. J Dent 2011; 39: 599-603.

58. Taha AA, Patel MP, Hill R G, Fleming PS. The effect of bioactive glasses on enamel remineralization: A systematic review. J Dent 2017; 67: 9-17.

59. Everett ET. Fluoride's effects on the formation of teeth and bones, and the influence of genetics. J Dent Res 2011; 90: 552-60.

60. Benson PE, Parkin N, Dyer F, Millett DT, Furness S, Germain P: Fluorides for the prevention of early tooth decay (demineralised white le- sions) during fixed brace treatment. Database Syst Rev 2013; 12: CD003809.

61. Bishara SE, Ostby AW. White spot lesions: formation, prevention, and treatment. Semin Orthod 2008; 14: 174-82.

62. Gokce G, Savas S, Kucukyilmaz E, Veli I. Effects of toothpastes on white spot lesions around orthodontic brackets using quantitative lightinduced fluorescence (QLF): An in vitro study. J Orofac Orthop 2017; 78: 480-6.

63. Farzanegan F, Morteza-Saadat-Mostafavi S, Ameri $\mathrm{H}$, Khaki $\mathrm{H}$. Effects of fluoride versus amorphous calcium phosphate solutions on enamel microhardness of white spot lesions: An in-vitro study. J Clin Exp Dent 2019; 11: e219-24.

64. Santos LF, Rego HM, Borges AB, Pucci CR, Torres CR. Efficacy of bleaching treatment on demineralized enamel treated with resin infiltration technique. World J Dent 2012;3:279-83.

65. Paris S, Schwendicke F, Keltsch J, Dorfer C, Meyer- Lueckel $\mathrm{H}$. Masking of white spot lesions by resin infiltration in vitro. J Dent 2013; 41: e28-34.

66 Shivanna V, Shikumar B. Novel treatment of white spot lesions: A report of two cases. J Conserv Dent 2011; 14: 423-6 11.Kim S, Kim EY, Jeong TS, Kim JW. The evaluation of resin infiltration for masking labial enamel white spot lesions. Int ] Paediatr Dent 2011; 21: 241-8.

67. Martignon S, Ekstrand KR, Gomez J, Lara JS, Cortes A. Infiltrating/ Sealing proksimal caries lesions: A 3-year randomized clinical trial. J Dent Res 2012; 91: 288-92.

68. Mueller J, Meyer-Lueckel H, Paris S, Hopfenmuller W, Kielbassa AM. Inhibition of lesion progression by the penetration of resins in-vitro: influence of the application procedure. Oper Dent 2006; 31: 338-45.

69. Senestraro SV, Crowe JJ, Wang M, Vo A, Huang G, Ferracane J, Covell DA. Minimally invasive resin infiltration of arrested white-spot lesions: a randomized clinical trial. J Am Dent Assoc 2013; 144: 997-1005.

70. Knösel M, Eckstein A, Helms HJ. Durability of esthetic improvement following Icon resin infiltration of multibracket-induced white spot lesions compared with no therapy over 6 months: a single- center, split-mouth, randomized clinical trial. Am J Orthod Dentofac Orthop 2013; 144: 8696.

71. Senestraro SV, Crowe JJ, Wang M, et al. Minimally invasive resin infiltration of arrested white-spot lesions: a randomized clinical trial. J Am Dent Assoc 2013; 144: 997-1005.

72. Yuan H, Li J, Chen L, Cheng L, Cannon RD, Mei L. Esthetic comparison of white-spot lesion treatment modalities using spectrometry and fluorescence. Angle Orthod 2014; 84: 343-9.

73. Prasada KL, Penta PK, Ramya KM. Spectrophotometric evaluation of white spot lesion treatment using novel resin infiltrationmaterial (ICON®). J Conserv Dent 2018; 21:531-5

74. Muthuvel P, Ganapathy A, Subramaniam M K, Revankar VD. Erosion infiltration technique': a novel alternative for masking enamel white spot lesion. J Pharm Bioallied Sci 2017; 9: S289-91.

75. Esteves-Oliveira M, Zezell DM, Meister J, Franzen R, Stanzel S, Lampert F, Eduardo CP, Apel C. CO2 laser (10.6 micron) parameters for caries prevention in dental enamel. Caries Res 2009; 43 : 261-8.

76. Steiner-Oliveira C, Rodrigues LK, Lima EB, Nobredos-Santos M. Effect of the $\mathrm{CO} 2$ laser combined with fluoridated products on the inhibition of enamel demineralization. J Contemp Dent Pract 2008; 9: 113-21. 
77.Rodrigues LK, Nobre Dos Santos M, Featherstone JD. In situ mineral loss inhibition by $\mathrm{CO} 2$ laser and fluoride. J Dent Res 2006; 85: 617-21.

78. Schmidlin PR, Dörig I, Lussi A, Roos M, Imfeld T. $\mathrm{CO} 2$ laser-irradiation through topically applied fluoride increases acid resistance of demineralized human enamel in vitro. Oral Health Prev Dent 2007; 5: 201-8.

79. Mahmoudzadeh M, Rezaei-Soufi L, Farhadian N, Jamalian SF, Akbarzadeh $M$, Momeni $M$, Basamtabar M. Effect of $\mathrm{CO} 2$ laser and fluoride varnish application on microhardness of enamel surface around orthodontic brackets. J Lasers Med Sci 2018;9:43-9.

80. Benbachir N, Ardu S, Krejci I. Indications and limits of the microabrasion technique. Quintessence Int 2007; 38:811- 5.

81. Barros Vasconcelos MQS, Vieira $K A$, da Consolacäo Canuto Salgueiro M, Almeida Alfaya T, Ferreira CS, Bussadori SK. Microabrasion: a treatment option for white spots. J Clin Pediatr Dent 2014; 39:27-9.

82. Pliska BT, Warner GA, Tantbirojn D, Larson BE. Treatment of white spot lesions with ACP paste and microabrasion. Angle Orthod 2012;82:765-9.

83. Gua $X$, Yang L, Yangc D, Gao Y, Duan X, Zhu X, Yuan $\mathrm{H}$, Li J. Esthetic improvements of postorthodontic white-spot lesions treated with resin infiltration and microabrasion: A split-mouth, randomized clinical trial. Angle Orthod 2019; 89: 372-7.

84. Sonesson M, Bergstrand F, Gizani S, Twetman S. Management of post-orthodontic white spot lesions: an updated systematic review. Eur J Orthod 2017; 39:116-21.

85. Pretty IA, Edgar WM, Higham SM. The effect of bleaching on enamel susceptibility to acid erosi- on and demineralisation. Br Dent J 2005;198:285-90.

86. Berger SB, Pavan S, Dos Santos PH, Giannini M, Bedran-Russo AK. Effect of bleaching on sound enamel and with early artificial caries lesions using confocal laser microscopy. Braz Dent J 2012; 23: 110- 5.

87. Attin T, Kielbassa AM, Schwanenberg M, Hellwig E. Effect of fluoride treatment on remineralization of bleached enamel. J Oral Rehabil 1997;24:282-6.

88. Jo Jo SY, Chong $\mathrm{HJ}$, Lee EH,Chang NY, Chae JM,Cho JH, Kim SC, Kang KH. Effects of various toothpastes on remin- eralization of white spot lesions. Korean J Orthod 2014; 44:113-8
89. Choi $Y$ Y, Lee $D Y$, Kimc $Y$ J. Colorimetric evaluation of white spot lesions following external bleaching with fluoridation: An in-vitro study. Korean J Orthod 2018; 48: 377-83.

90. Uysal S, Öz F T. Derleme: başlangıç mine lezyonlarının remineralizasyonunda kullanılan ajanlar. A Ü Diş Hek Fak Derg 2018; 45: 201-10.

\section{Sorumlu Yazarın Yazışma Adresi}

Prof. Dr. Nurdan Meserret BAŞEREN

Hacettepe Üniversitesi Diş Hekimliği Fakültesi, Ankara.

E-Posta adresi meserret@hacettepe.edu.tr 